EPJ Web of Conferences 45, 01023 (2013)

DOI: $10.1051 /$ epjconf/20134501023

(C) Owned by the authors, published by EDP Sciences, 2013

\title{
In-situ Modelisation of a Greenhouse Climate Including Sensible Heat, Water Vapour and $\mathrm{CO}_{2}$ Balances
}

\author{
B. Draoui ${ }^{1}$, F Bounaama $^{1}$, T. Boulard ${ }^{2}$ and N. Bibi-Triki ${ }^{3}$ \\ ${ }^{1}$ Arids zones energetic laboratory -(ENERGARID) University of Bechar, BP 417, 08000 Bechar Algeria \\ ${ }^{2}$ I.N.R.A. - Bioclimatic station - B.P. 91, 84143 Montfavet Cedex,French) \\ ${ }^{3}$ Research unit on materials and renewable energy, U.R.M.E.R Abou bakr Belkaïd University, B.P. 119, Tlemcen, \\ Algeria
}

\begin{abstract}
While thermal structures such as greenhouses are complex to model under transient conditions because of coupled heat and mass $\left(\mathrm{H}_{2} \mathrm{O}\right.$ and $\left.\mathrm{CO}_{2}\right)$ exchanges between their different parts, systems theory allows a simple analysis of the input/output behaviour of the model. In particular, parameters of the reduced dynamic models can be derived from in-situ measurements on these systems. This paper describes an application of the systems approach to a greenhouse climate model which incorporates $\mathrm{CO}_{2}$ balance, crop transpiration and photosynthesis and the effects of heating, $\mathrm{CO}_{2}$ enrichment, natural ventilation and evaporative cooling. In a first stage, system parameters such as the equivalent thermal mass, the wind dependent coefficient of natural ventilation and the various heat exchange coefficients were identified in situ from sequences of input-output data concerning the heat and water vapour balance, recorded over the crop production period from December to July. Good agreement between measured and computed values of air temperature, air humidity was observed. In a second stage, we have considered simultaneously the sensible heat, water vapour and $\mathrm{CO}_{2}$ exchanges and tested the model against experimental data measured using a commercial greenhouse climate control computer. The identified values of the physical and physiological parameters are close the theoretical values and the accuracy of temperature, humidity and $\mathrm{CO}_{2}$ content is rather good.
\end{abstract}

\section{Introduction}

Mathematical simulation models of the inside climate greenhouses have primarily focused on the determination of heating systems and other systems of climate control have been largely ignored although they play an important role. These other systems include natural ventilation, evaporative cooling, shading, and $\mathrm{CO}_{2}$ enrichment and irrigation control. Analysis of these systems requires additional considerations on water vapour and $\mathrm{CO}_{2}$ balances and on the coupled mechanisms involving heat and mass (air, water vapour and $\mathrm{CO}_{2}$ ) balances. Dynamic numerical models describing those processes are complex and not easy to use in practice as they require (knowledge of) a large number of model parameters [1] and the algorithms of research of the solutions can often diverge if the choice of initial conditions is wrong. Knowing the parameters of the model is particularly critical because in contrast to most other thermal systems, greenhouse parameters are constantly evolving: radiative transfers properties are modified by the presence of dust, hydric factors such as the wetted surface, water vapour transfers and soil or crop water content are time dependent as are biological parameters such as crop architecture, LAI, crop-water status and stomatal conductance. It explains why complex dynamic models are seldom used for greenhouse climate control. This paper presents the theory and methods involved in the development of a reduced thermal and mass (water vapour and $\mathrm{CO}_{2}$ ) model of the greenhouse and in-situ identification of model parameters. Experimental validation of the method in production conditions will be presented and values of the identified parameters discussed.

\section{The identification problem}

Modeling has two components: incorporating accumulated knowledge from the past and confronting the model with current data. The first takes the form of established relations and handbook sets of parameters. The second involves calibration or, in a wider sense, model system identification from data, which ideally can reveal alternate model structures as well, thus serving as

마bdraoui@yahoo.com

This is an Open Access article distributed under the terms of the Creative Commons Attribution License 2.0, which permits unrestricted use, distribution, and reproduction in any medium, provided the original work is properly cited. 
hypothesis testing. However, it is well known from systems theory that a particular input-output behavior might be represented by alternative state-space representations [2]. As already exposed with more details in a previous paper [3], identification techniques in the case of greenhouse requires a system approach of thermal and mass transfers which are described by 4 types of values related to the greenhouse and its environment: the entry vector $U(t)$, which describes the conditions from which the system evolves; the output vector $Y(t)$, or the ensemble of the state variables which can be observed and measured; the current state of the system $X(t)$, which includes all the state variables of the system allowing as a function of time and the vectors of unknown system parameters. The dynamic behavior of the system can be described by a set of 2 equations:

$\frac{\mathrm{dx}(\mathrm{t})}{\mathrm{dt}}=f(x(t), u(t), p)$

the observation equation is:

$y(t)=g(x(t), u(t), p)$

If $J$ is the difference between model and process output, the optimization problem to be solved for parameters identification is to find a vector of parameters $p$ such that the criterion little than $\varepsilon$.

\section{The identification algorithm}

The model performance is evaluated using a minimization criterion $(J)$ which estimates the standard variation between measured $(Y)$ and estimated $\left(Y^{*}\right)$ values of the output vector: For the coupled heat and water balance, J will be denoted Jtot as it represents the sum of the standard deviations of the sum of air temperature, water vapour and $\mathrm{CO}_{2}$ pressure, correctly weighed in order to create the same order of magnitude. This method, based on Marquardt's algorithm, consists of choosing alternately and judiciously between a gradient method and least square method in order to progress in the direction of solutions which minimize Jtot [4]. The program, written in Fortran, is called LADYS (Logiciel d'Analyse DYnamique des Serres :

Algorithm for Dynamic Modeling of Greenhouse) and allows to identify the parameter values together with their interval of confidence. These methods have been applied to the greenhouse climate with its complications of biological processes [3] including coupling between heat and water vapour transfers and crop transpiration; it is now extended to the whole greenhouse heat and mass balance including the $\mathrm{CO}_{2}$ balance.

\section{Physical modeling of greenhouse climate}

In order to reduce the system order of the thermal model, we have considered an empirical approach based on consideration of the characteristic time scales of each thermal component of the system. We have then considered two main components:
In order to reduce the system order of the thermal model, we have considered an empirical approach based on consideration of the characteristic time scales of each thermal component of the system. We have then considered two main components:

- soil and heavy structural elements, with characteristic time scale much longer than our observation time scale; they will be collectively gathered under the appellation of a virtual thermal mass characterized by a virtual temperature $T_{m}$ and thermal capacity $C_{m}$;

- the crop, greenhouse superstructure and the enclosed air space, whose characteristic time scale is low $\left(\tau_{\mathrm{c}, \min } \approx 200\right.$ $\left.\mathrm{s}, \tau_{\mathrm{c}, \max } \approx 500 \mathrm{~s}\right)$ compared to our observation time scale (3600s or $900 \mathrm{~s}$ ) and will be characterized by temperature $T_{i}$ and water vapour pressure $p_{i}$.

\section{Virtual thermal mass:}

$$
C_{m} \frac{d T_{m}}{d t}=h\left(T_{i}-T_{m}\right)+Q_{s o l}+\beta R g
$$

Where the first term on the right hand side is the exchange with the greenhouse air, the second one the soil heating and the last one the solar gain directly absorbed by the thermal mass.

Air thermal balance:

$$
\begin{aligned}
& 0=\alpha R g+Q_{\text {air }}+h\left(T_{m}-T_{i}\right)+K\left(T_{o}-T_{i}\right) \\
& +K_{s}\left(T_{o}-T_{i}\right)+K_{l}\left(P_{o}-P_{i}\right)
\end{aligned}
$$

where the first term of the right hand side is the solar gain, the second one, the air heating, the third one, the thermal exchange with the thermal mass, the fourth one the overall heat exchange between inside and outside, the fifth and the last one, the sensible and latent heat exchanges by ventilation and leakages.

Air water vapour balance:

$$
C_{l} \frac{d P_{i}}{d t}=A \tau R g+B\left(P^{*}\left(T_{i}\right)-P_{i}\right)-K_{l}\left(P_{i}-P_{o}\right)+\varphi_{l}
$$

Where the first term of the right hand side represents the crop transpiration (simply described as a linear function of global radiation and saturation deficit [5]), the second one the exchanges by ventilation and the last one the contribution of the fog system.

\section{Air $\mathrm{CO}_{2}$ balance:}

$$
\frac{v g}{S} \frac{d C i}{d t}=\frac{S c}{S} p_{n}-\frac{G v}{S}(C i-C o)+E n
$$

The variables: $P_{n}$ and En represent the photosynthesis parameters.

where the first term of the right hand side is the net photosynthesis, the second one is the exchanges by ventilation and the last one the enrichment. $P_{n}$ the net photosynthesis combines a large number of biological parameters (LAI, etc) and involved the Photosyntheticaly 
Active Radiation (the PAR is linearly deduced of $R_{g}$ taken at the same time step). Simultaneous integration of the equations of energy (eq.3 and 4) and water vapour balances and $\mathrm{CO}_{2}$ (eq.5 and eq.6) leads to a system of 4 equations with 3 unknowns ( $\mathrm{Tm}, \mathrm{Ti}, \mathrm{Pi}, \mathrm{Ci})$ which can be presented in a recursive form as a function of the past (time $n$ ), the instantaneous input vectors

( $R g, T_{0}, V, P_{0}, P *(T i), C o$ ), of the command variables $\left(Q_{\text {sol }}, Q_{\text {air }}, E n\right.$, and $\left.\varphi_{l}\right)$ and of model parameters (included in the matrices line) which are partially to be identified.

The complete system can be represented is as follows:

$$
\begin{aligned}
& C_{i(n+1)}=C_{i(n)} \exp (-\eta \Delta t)+(1-\exp (-\eta \Delta t))\left(1 \frac{S c P n}{G v S c} \frac{1}{G v}\right)\left(\begin{array}{l}
C_{o} \\
1 \\
E_{n}
\end{array}\right) \\
& P_{i(n+1)}=P_{i(n)} \exp (-\zeta \Delta t)+ \\
& (1-\exp (-\zeta \Delta t))\left(\frac{r S B \gamma \tau^{\prime}}{\xi} \frac{\chi}{\xi} \frac{\gamma S B}{\xi} \frac{\gamma S}{\xi}\right)\left(\begin{array}{l}
R_{g} \\
P_{O} \\
P^{*}(T i) \\
\varphi_{l}
\end{array}\right) \\
& T_{m(n+1)}=T_{m(n)} \exp \left(-\frac{\Delta t}{\tau}\right)+\left(1-\exp \left(-\frac{\Delta t}{\tau}\right)\right) \times \Psi \times\left(\begin{array}{l}
T_{o} \\
R_{g} \\
Q_{\text {sol }} \\
Q_{\text {air }} \\
P_{O} \\
P_{i}
\end{array}\right)
\end{aligned}
$$

With the variable $\Psi$ is defined as

$$
\begin{array}{r}
\Psi=\left(1 \frac{\alpha h+\beta v}{h\left(K+K_{S}\right)} \frac{v}{h\left(K+K_{S}\right)} \frac{1}{\left(K+K_{s}\right)} \frac{K_{l}}{\left(K+K_{S}\right)} \frac{-K_{l}}{\left(K+K_{l}\right)}\right) \\
T_{i(n+1)}=\frac{h}{v} T_{m(n+1)}+\left(\frac{v-h}{v} \frac{\alpha}{v} \frac{1}{v} \frac{K_{l}}{v} \frac{-K_{l}}{v}\right)\left(\begin{array}{l}
T_{o} \\
R_{g} \\
Q_{a i r} \\
P_{o} \\
P_{i}
\end{array}\right)
\end{array}
$$

The variables: $\xi, \eta, \delta, \zeta, v$ represent combinations of physical and biological parameters.

\section{1. Experimental conditions}

Experiments were performed between April and July in a double roof plastic house of $416 \mathrm{~m}^{2}$ occupied by a tomato-crop and situated near Avignon in south-east France. The experimental verification was performed in two steps: in a first step, we have identified the parameters of the thermal and water vapour balances by means of measurements performed by a very accurate data logger and sensors $\left( \pm 0.1^{\circ} \mathrm{C}\right.$ for $\mathrm{T}, \pm 5 \mathrm{Wm}^{-2}$ for Global Radiation) whereas, in a second step we have performed the same operation on the thermal, water vapour and $\mathrm{CO} 2$ balances using the measurements much less accurate performed in the conditions of production by the data logger and sensors $\left( \pm 0.5^{\circ} \mathrm{C}\right.$ for
$T, \pm 15 \mathrm{PPm}$ for $C, \pm 20 \mathrm{Wm}^{-2}$ for Global Radiation $R_{g}$ ) of a commercial greenhouse climate control computer.

\section{2. Coupled heat and water vapour balances}

The large number of parameters (12 with $T_{m}(0)$ and $\left.p_{i}(0)\right)$, led us to hold constant those parameters whose values could be determined by other means. They were ventilation and leakages coefficients $\left(A l \sqrt{C}, s_{0}\right.$ and $d_{0}$ ) which were obtained using tracer gas methods and $K$ is the overall heat loss coefficient. As illustrated by table 1 , values of the identified parameters are coherent with those found in the literature and the criterion values (Jtot) shows that the estimation of both $T_{i}$ and $p_{i}$ is rather good.

The variables: $\alpha, \beta, h, K, K s, \varphi_{l}, G_{v}, C_{l}$, represent combinations of physical parameters.

\section{3. Complete heat, water vapour and $\mathrm{CO}_{2}$ balances}

The thermal, $\mathrm{CO}_{2}$ and water vapour balances involve 14 parameters (the 12 parameters of the coupled heat and water vapour balance plus the LAI and $\lambda$ the efficiency of photosynthesis). We have identified only 5 parameters, the other being considered as known and constant. They were the thermal capacity $C_{m}$, the transfer coefficient between air and thermal mass: $h$, the rate of absorption of global radiation $\alpha$ and the leaf area index LAI. The identified values of $C_{m}, h$ and $\alpha$ are in agreement with the values identified with only the thermal and water vapour balance. The identified value of LAI (1.45) is close to the measured value (1.8), where the relative error is $20 \%$. Figures (1,2 and 3) illustrate the good estimation of $T_{i}, p_{i}$ and $C_{i}$ with a respectively accuracy of values: $1.64{ }^{\circ} \mathrm{C}$ for $\mathrm{Ti}, 1.56 \mathrm{hPa}$ for $p_{i}$ and $1.1210^{-4} \mathrm{Kg}$ $\mathrm{m}^{-3}$ for $C_{i}$.

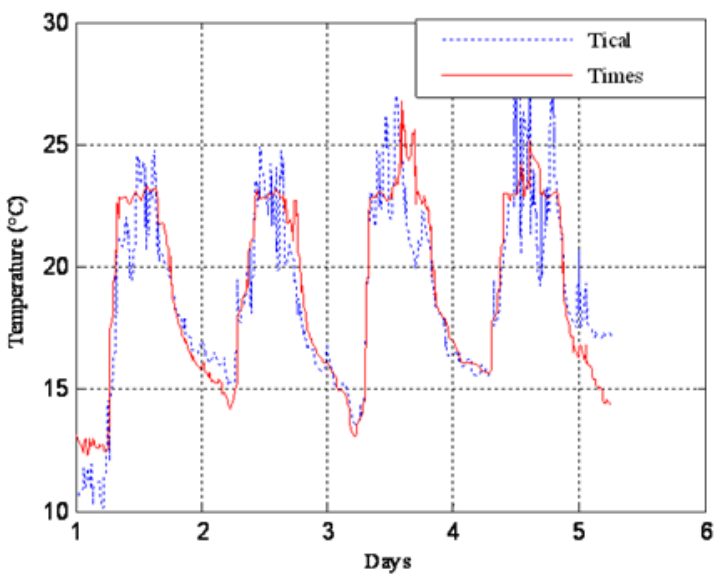

Fig.1. Greenhouse air temperature 


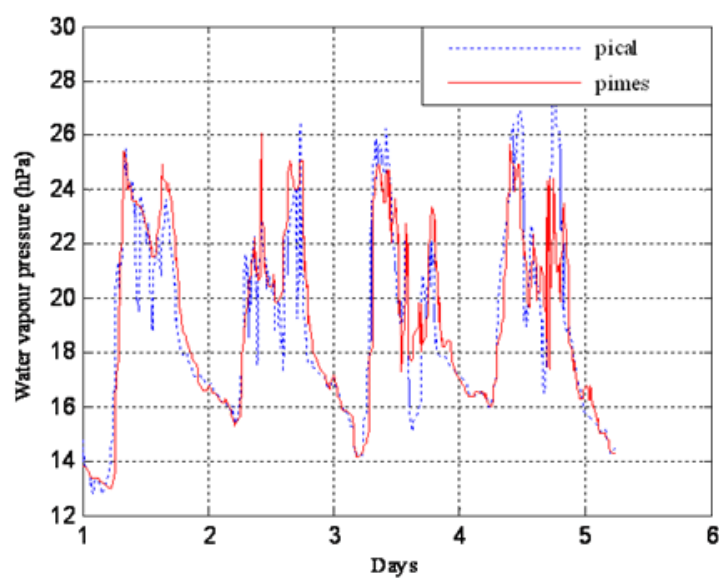

Fig.2. Greenhouse air water vapour pressure

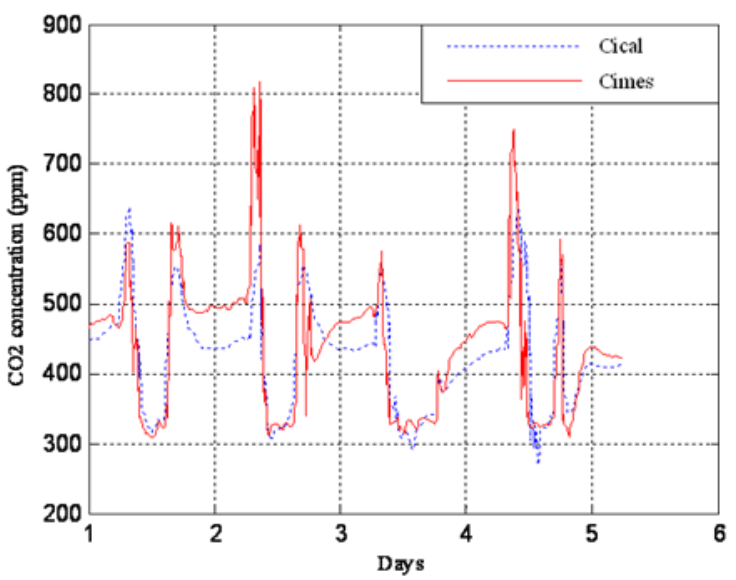

Fig.3. Greenhouse air carbon dioxide

Measured values ( $T_{\text {imes }}, P_{\text {imes }}$, and, $\left.C_{\text {imes }}\right)$, by means of the sensors of a commercial greenhouse climate control computer, and calculated values $\left(T_{i c a l}, P_{i c a l}\right.$, and $\left.C_{i c a l}\right)$, after identification of the model parameters. Culture: tomato crop $(\mathrm{LAI}=1.8)$; sequences: 4 days of April.

\section{Conclusions}

This (theoretical and experimental) study has shown that the systems approach and the principles of identification can be transferred to the greenhouse energy; water vapour and $\mathrm{CO}_{2}$ balance modeling. Both the sensible heat balance as well as water vapour and $\mathrm{CO}_{2}$ balances can be described adequately by a reduced dynamic model. Insitu identification of physical and crop parameters were performed on a greenhouse- crop system during whole crop duration. Though we can state very large variations with the time of the identified values of the thermal balance, numerical values of these parameters were coherent both from physical and physiological points of view and allowed computation, with a rather good precision, of inside air temperature, humidity and $\mathrm{CO}_{2}$ concentration. Estimation of crop transpiration and photosynthesis was another output of the model. If we want to keep a physical or physiological meaning to the identified parameters, a maximum of 5 parameters can be identified. In addition, it is shown, that the accuracy of the input, output measurements conditions widely the accuracy of the model estimation.

\section{References}

1. Morimoto, T., and Y. Hashimoto. AI approaches to identification and control of total plant production systems. Control Engineering Practice 8 (5); (2000)

2. G.van Straten, G. van Willigenburg, E. van Henten and Rachel van Ooteghem. Optimal control of greenhouse cultivation, CRC Press is an imprint of the Taylor \& Francis Group, an informa business, U.S.A (2011)

3. Boulard (T.), Draoui (B.) and Neirac (F.). Calibration and validation of a greenhouse climate control model, Workshop: Mathematical \& Control Applications in Agriculture and Horticulture, Silsoe, Grande Bretagne, Acta Horticulturae, (1994)

4. Cools (C.), Gicquel (R.) and Neirac (F.). Identification of building reduced models. Application to the characterization of Passive Solar Components, International Journal of Solar Energy, Vol. 7, N³, (1989)

5. Boulard (T.) and Jemaa (R.). Greenhouse tomato crop transpiration model: application to irrigationcontrol. Acta Horticulturae, 335, (1993)

6. Acock (B.), Charles-Edwards (D.A.), Fitter (D.J.), Hand(D.W.), Ludwig(L.J.), Warren Wilson (J.), Withers(A.C.) The contribution of leaves from different levels within a tomato crop to canopy net photosynthesis : an experimental of two canopy models. J. Exp. Bot. 29 (111), (1978) 
EFM 2012

Table 1 - Identified values of parameters of the coupled model Eq 8, 9 and 10

\begin{tabular}{|c|c|c|c|c|c|c|c|}
\hline Period & $\begin{array}{c}\mathrm{T}_{\mathrm{m} 0}[ \\
\left.{ }^{\circ} \mathrm{C}\right]\end{array}$ & $\mathrm{C}_{\mathrm{m}}\left[\mathrm{kJ} \cdot \mathrm{m}^{-2} \cdot \mathrm{K}^{-1}\right]$ & $\mathrm{H}\left[\mathrm{W} \cdot \mathrm{m}^{-2} \cdot \mathrm{K}^{-1}\right]$ & $\alpha$ & $\mathrm{B}\left[\mathrm{W} \cdot \mathrm{m}^{-2} \cdot \mathrm{hPa}^{-1}\right]$ & $\tau[\mathrm{h}]$ & criterionJtot $\left[{ }^{\circ} \mathrm{C}+\mathrm{hPa}\right]$ \\
\hline April & $18^{*}$ & $\begin{array}{c}294 \\
\pm 317\end{array}$ & $\begin{array}{c}2.34 \\
\pm 0.59\end{array}$ & $\begin{array}{c}0.24 \\
\pm 0.02\end{array}$ & $\begin{array}{c}7.64 \\
\pm 0.78\end{array}$ & 45.6 & 2.67 \\
\hline May1 & $20 *$ & $\begin{array}{c}518 \\
\pm 352.5\end{array}$ & $\begin{array}{c}4.7 \\
\pm 0.96\end{array}$ & $\begin{array}{c}0.36 \\
\pm 0.02\end{array}$ & $\begin{array}{c}9.15 \\
\pm 1.22\end{array}$ & 49.5 & 1.77 \\
\hline June & $21 *$ & $27 \pm 35$ & $\begin{array}{c}1.43 \\
\pm 0.60\end{array}$ & $\begin{array}{c}0.23 \\
\pm 0.04\end{array}$ & $\begin{array}{c}5.40 \\
\pm 0.85\end{array}$ & 6.2 & 2.13 \\
\hline July & $22 *$ & $15 \pm 46$ & $\begin{array}{c}1.34 \\
\pm 1,43\end{array}$ & $\begin{array}{c}0.35 \\
\pm 0.08\end{array}$ & $\begin{array}{c}6.20 \\
\pm 1.26\end{array}$ & 3.6 & 2.04 \\
\hline $\begin{array}{l}\text { Values of } \\
\text { the } \\
\text { literature }\end{array}$ & & 80 to 300 & 10 to 20 & 0.3 to 0.4 & 5 to 12 & & \\
\hline
\end{tabular}

